\title{
THE EFFECT OF CORE STABLLITY AND FUNCTIONAL EXERCISES ON SELECTED SPEED AND STRENGTH PARAMETERS IN EXPERT FEMALE FOOTBALLERS
}

\author{
Natalia Niewolna, $A, B, C, D$ Teresa Zwierko ${ }^{A, D, E}$ \\ Faculty of Physical Culture and Health Promotion, University of Szczecin, Poland

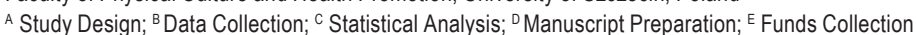 \\ Address for corpespondence: \\ Natalia Niewolna, MSc \\ University of Szczecin, Faculty of Physical Culture and Health Promotion \\ Al. Piastów 40 b, building 6, 71-065 Szczecin, Poland \\ E-mail: natalia-niewolna@o2.pl
}

\begin{abstract}
Ahstract. Designed to strengthen the deep (stabilizer) muscles which stabilize joints and ligaments, core stability exercises are important for the development of motor skills in athletes. In this research, we aimed to determine how a two-year program of core stability and functional exercises influenced the strength and speed of female football players. The tested athletes $(n=17)$ were members of Olimpia Szczecin MKS, a first division football club from Poland. Their mean age was $19.8 \pm 1.4$ years, while the mean duration of sport experience was 6 years. We analyzed their running speed, as well as the maximal strength of eight major muscle groups: rectus abdominals, abdominal oblique, shoulder girdle, chest, upper limbs, quadriceps, biceps and gastronomies. The effects of training on motor speed and strength were measured twice, prior to each of the two seasons. The functional training resulted in significant changes in the strength of various muscle groups: quadriceps $(\Delta 17.1 \mathrm{~kg} ; \mathrm{p}<0.05)$, abdominal oblique muscle $(\Delta 9.1 \mathrm{~kg}$; $p<0.05)$, shoulder girdle $(\Delta 3.6 \mathrm{~kg} ; p<0.05)$ and chest $(\Delta 3.5 \mathrm{~kg} ; p<0.05)$. There was also a significant reduction in the time of the 30 meter sprint $(p<0.05)(\Delta 0.1 \mathrm{~s} ; p<0.05)$. In summary, functional training had a positive effect on the strength and running speed of the tested female footballers.
\end{abstract}

Key Worlls: core stability, functional training, motor effects, football

\section{Introduction}

Football places high demands on players in terms of their motor performance, essential for the effective execution of technical and tactical tasks. The necessary motor skills can be improved by core stability exercises which involve strengthening of the deep(stabilizer)muscles responsible for stabilizing the joints and ligaments. Importantly, any malfunction in the deep muscles also negatively affects the superficial muscles that are directly responsible for body movements. As a result, poor coordination between these two groups of muscles may result in injuries and disorders in the muscle tension distribution, directly affecting motor performance. Dealing with this 
deficiency in neuronal-muscular coordination and in economy of movement is yet another role of core stability exercises (Sharmann 2002; Boyle 2004; Paterno et al. 2004).Systematic core stability exercises have been used in relation to back pain and rehabilitation and to decrease the risk of injury (Beam 2002; Clark 2001; Duncan et al. 2000; Haynes 2004; Wilson et al. 2005).The number of recent studies has identified the importance of a strong core in relationto improve sport performance (Nesser et al. 2008; Sato and Mokha 2009; Sharrock and Cropper 2011). In a review on the efficiency of core stability exercises, Reed and Ford 2012) indicated that most reports reveal a significant effect of stability exercises on the strength of legs and the height of vertical jumps. Nesser et al. (2008) attempted to analyze the effects of core stability exercises and motor performance in footballers to determine connections between core stability and the individual elements of fitness. Correlation analysis showed a significant effect $(p<0.05)$ of total core muscle strength on 20 and 40 yard sprint times, 10 -yd shuttle run, squats and countermovement vertical jump. The obtained results showed a significant effect of core stability exercises on the performance of athletes. Furthermore, Sato and Mokha (2009) analyzed the influence of core strength training on running kinetics, lower extremity stability, and performance in runners. They observed that core stability exercises did not significantly influence kinetic efficiency and lower extremity stability, but did influence running performance (5000 m). On the other hand, Ścibek et al. (2001) investigated the effect of Swiss ball training on core stability and subsequent swim performance. Their results reported enhanced core stability, which did not transfer into improved swim times. Similarly Stanton et al. (2004) have reviewed running performance, economy, and core strength in high school-aged touch football and basketball athletes. Groups from this study completed core training, and groups that underwent training experienced improvements in core strength but did not show improvements in running performance. Tse et al. (2005) tested rowing performance and core endurance in college-age rowers. After training period (2 days per week for 8 weeks) core endurance training program improved selected core endurance parameters in athletes, but the effectiveness of the core intervention on various functional performance aspects(vertical jump, broad jump, shuttle run, 40 -m sprint, overhead medicine ball throw, 2,000-m maximal rowing ergometertest) was not supported.

According to previous research, relationships between core strength/stability and sport performance is not clear. Therefore, the purpose of this study was to identify a relationship between core stability and functional exercisesandmotor performance. The effect of core stability exercises on motor skills is very interesting not only from the general scientific point of view, but also in terms of direct application in football training. Its significance in sports theory and practice is the main premise behind this research on the strength and speed of female football players, with the following specific objectives:

1. Determination of changes in strength over a two year period in football training supported by core stability and functional exercises.

2. Determination of changes in 30 meter sprint times resulting from the core stability and functional training program.

\section{Material and Methods}

The research was carried out on 17 female players of the first division football club MKS Olimpia Szczecin. The mean age was $19.8 \pm 1.4$ years, with a mean sporting career of 6 years. All the tested players were included in the same training plan, including 5 training units in a week-long micro-cycle of the season, always finishing with a match. The preparation period lasted 3 months in which the players were subjected to a program of 3 stability 
and functional exercises a week, 20 minutes each session (Stein 2008). During the season, stability and functional exercises were performed twice a week, and theoffseason workout period included one training unit with key exercises. The measurements of strength and speed were performed prior to the start of the preparation period before each season. The measurements of speed were made on 8 January 2014 and 5 January 2015, while maximal strength was measured on 9 January 2014 and 6 January 2015. The procedures followed in the study were approved by the Ethics Committee of the Regional Medical Chamber in Szczecin (Approval number 02/KB/V/2015).

a)

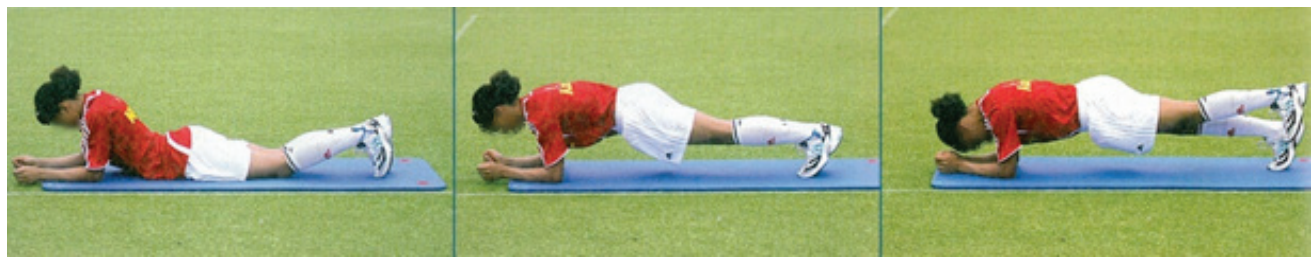

b)

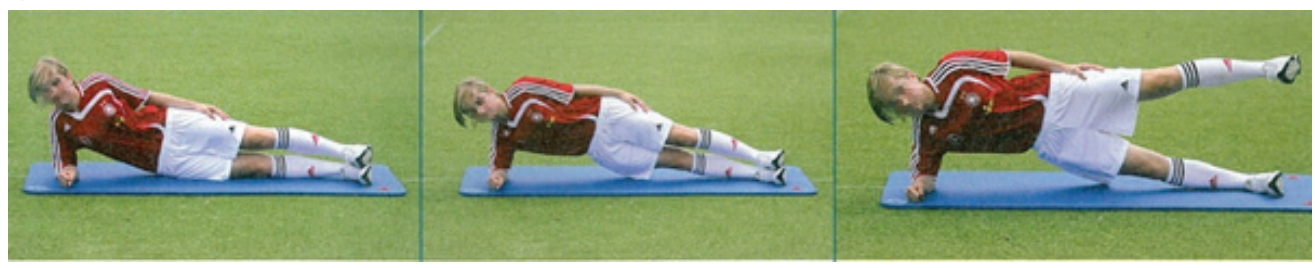

c)

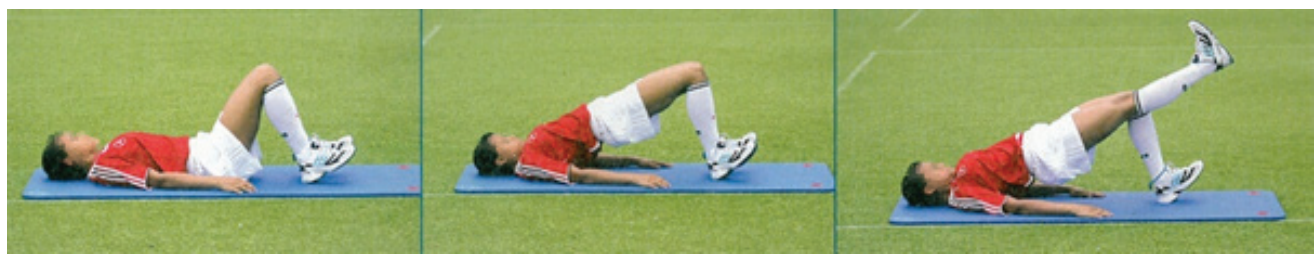

Figure 1. Representative examples of functional and core stability exercises (Stein 2008)

The measurement of speed was performed on a straight section of running track (30 meters) with the use of photo-cells (TS - F5) placed at the beginning and the end of the track. The photo-cells were mounted at a height of $1.20 \mathrm{~m}$. The tested football players started their sprint without any audio or visual signal; they themselves decided when to start running. Each participant ran twice, and the better result of the two was recorded. The interval between the repetitions was 4 minutes, which allowed for a full recovery before the second attempt.

The examinations of abdominal strength were performed at a gym by measuring the level of maximal strength (apparatus for measuring - Technogym) of eight muscle groups: rectus abdominal muscle, abdominal oblique muscle, shoulder girdle, chest, upper limb muscles, quadriceps, biceps and gastrocnemius muscle. The determination of maximal strength was carried out in three training units, and the players used trial and error to lift a maximal load. 
Each test wasfully assisted by the other participants. After the general warm-up program, participants performed a specific warm-up including submaximal intensity performance for all tested exercises, at levels of 50,75 , and $85 \%$ of the $1 \mathrm{RM}$ (one repetition maximum) for each participant. The relevant repetitions for each selected intensity were 12,8 , and 3 respectively. Two sets were performed for each selected intensity. After that, resistance was gradually increased from a critical value $5 \%$ below the expected $1 \mathrm{RM}$. After each successful performance the intensity was gradually increased by $2 \%$ until failure in lifting of the same load was observed. Interval between repetitions was 3 minutes. For the final estimation of 1RM, 3-6 trials were used. Failure was de-fined when participants failed to perform the full range of motion of the selected exercise on at least 2 attempts. The full range of motion was defined by lifting the bar without any additional load. All testing procedures were closely supervised.

The measurements of strength and speed were preceded by an appropriate warm-up at a moderate intensity, finishing with dynamic stretching. The obtained results were recorded and written down in files. The participants wore sport shoes and clothes. In addition, the players were asked to perform at maximal effort during the tests. The collected material was subjected to basic statistical analysis with the use of the Statistica 10 software. The results were described with the methods of descriptive statistics. The differences between the results were evaluated with a Student's t-test for dependent variables. The level of significance was established at $p<0.05$.

\section{Results}

The study was based on the measurements of the time of sprint over $30 \mathrm{~m}$, as well as the maximal strength of eight major muscle groups: rectus abdominis muscle, abdominal oblique muscle, shoulder girdle, chest, upper limb muscles, muscles, quadricepsfemoris, bicepsfemoris and gastrocnemius muscle.

Table 1. Mean maximal strength and results of the Student's t-test $(n=17)$

\begin{tabular}{|c|c|c|c|}
\hline Musclegroup & Measurement & $\bar{x} \pm S D$ & Student's t-test \\
\hline \multirow{2}{*}{ Quadriceps femoris } & 1 st measurement & $141.8 \pm 36.4$ & \multirow{2}{*}{$3.40^{*}$} \\
\hline & 2 nd easurement & $158.8 \pm 34.6$ & \\
\hline \multirow{2}{*}{ Abdominal oblique muscle } & 1 st measurement & $43.8 \pm 7.8$ & \multirow{2}{*}{$4.73^{\star}$} \\
\hline & 2 nd measurement & $52.9 \pm 13.1$ & \\
\hline \multirow{2}{*}{ Chest } & 1 st measurement & $30.9 \pm 9.2$ & \multirow{2}{*}{$2.70^{*}$} \\
\hline & $2 \mathrm{nd}$ measurement & $34.5 \pm 6.6$ & \\
\hline \multirow{2}{*}{ Shoulder girdle } & 1 st measurement & $52.9 \pm 8.7$ & \multirow{2}{*}{$2.30^{*}$} \\
\hline & 2 nd measurement & $56.5 \pm 10.9$ & \\
\hline \multirow{2}{*}{ Biceps femoris } & 1 st measurement & $55.0 \pm 8.5$ & \multirow{2}{*}{1.85} \\
\hline & 2 nd measurement & $57.6 \pm 11.1$ & \\
\hline \multirow{2}{*}{ Rectus abdominis muscle } & 1 st measurement & $50.2 \pm 12.1$ & \multirow{2}{*}{0.73} \\
\hline & 2 nd measurement & $51.5 \pm 10.9$ & \\
\hline \multirow{2}{*}{ Gastrocnemius muscle } & 1 st measurement & $178.2 \pm 23.0$ & \multirow{2}{*}{1.29} \\
\hline & $2 \mathrm{nd}$ measurement & $170.9 \pm 28.8$ & \\
\hline \multirow{2}{*}{ Upper limbs } & 1 st measurement & $36.8 \pm 6.6$ & \multirow{2}{*}{1.56} \\
\hline & $2 \mathrm{nd}$ measurement & $38.5 \pm 7.5$ & \\
\hline
\end{tabular}

There were significant changes in maximal strength in 4 muscle groups: quadricepsfemoris $(\Delta 17.1 \mathrm{~kg}, 141.8 \mathrm{~kg}$ vs. $158.8 \mathrm{~kg}, p<0.05)$, abdominal oblique muscle (43.8 kg vs. $52.9 \mathrm{~kg}, p<0.05)$, shoulder girdle $(52.9 \mathrm{~kg}$ vs. $56.5 \mathrm{~kg}$, 
$p<0.05)$ and the chest $(30.9 \mathrm{~kg}$ vs. $34.5 \mathrm{~kg}, \mathrm{p}<0.05)$ (Table 1). In the rest of the studied muscle groups: biceps femoris, rectus abdominis muscle, chest, gastrocnemius muscle, and upper limbs muscles, we found no significant changes in the studied strength parameters.

Analysis of $30 \mathrm{~m}$ sprint results also showed a positive effect of stability and functional training on speed. The results of the first and second measurement showed a significant reduction in sprint time over $30 \mathrm{~m}$ in the analyzed group of female footballers (4.32 s vs. $4.22 \mathrm{~s}, \mathrm{p}<0.05)$.

Tahle 2. Mean sprint time over $30 \mathrm{~m}$ and the Student's t-test results $(n=17)$

\begin{tabular}{lccc}
\hline \multirow{3}{*}{$30 \mathrm{~m}$ sprint time } & Measurement & $\overline{\mathrm{x}} \pm$ SD & Student's t-test \\
\cline { 2 - 4 } & 1st measurement & $4.32 \pm 0.23$ & \multirow{2}{*}{$2.13^{*}$} \\
\hline${ }^{*} p<0.05$. & 2nd measurement & $4.22 \pm 0.25$ & \\
\hline
\end{tabular}

\section{Discussion}

In this study we observed an improvement in motor skills over the duration of the stability and functional training. This trend concerned quadriceps femoris, abdominal oblique muscle, shoulder girdle and the chest, as well as in the sprint time. Our observation confirmed previous study results that systematic core stability and functional exercises have positive effects on motor performance (Nesser et al. 2008; Sato and Mokha 2009; Sharrock and Cropper 2011). However, the lack of statistically significant changes in maximal strength in the rest of the categories (biceps femoris, rectus abdominis muscle, gastrocnemius muscle, upper limbs) was probably due to the method of implementing the core stability and functional exercises. According to its author (Stein 2008), the program is governed by the 'trunk before limbs' principle. Only the well-developed muscles of the abdomen and back create a necessary 'corset' for high performance of the arms and legs. Thus the stable trunk and coordination obtained are very significant in football and other sports; allowing for a more efficient energy transfer and directly helping to maintain correct posture and silhouette. Otherwise, if a player first improves the stability of the limbs while neglecting the trunk (lumbar-pelvis-femoral complex), this may lead to adverse compensatory habits and, in consequence, overloading and injuries (Clark 2001; Haynes 2004). In this study, the point of departure in the annual scheme of training was to stabilize the trunk first, and then the upper and lower limbs, leading to an observed lack of statistically significant changes in the maximal strength of the muscles: gastrcnemius, biceps femoris and the upper limbs.

The comprehensive program of core stability exercises resulted in efficient motor performances in football, a sport which requires the work of the entire body. During various actions in the match, the body functions as the comprehensive system of elements connected by joints and tissues. There are practically no movements in this sport that involve only selected muscles. As the natural football form of movements involves almost all joints and groups of muscles, footballers benefit from stability and functional training.

It should be mentioned that despite the lack of statistically significant changes in some muscle groups, we observed a considerable improvement in maximal strength of the biceps femoris (by $2.6 \mathrm{~kg}$ ), upper limbs (by $1.7 \mathrm{~kg}$ ) and rectus abdominis muscle(by $1.3 \mathrm{~kg}$ ) (Table 1).Probably, continuationof the stability and functional exercise by the studied players would lead to a number of further improvements in the results of measurements. 
The results of our study suggest that the improvements in sprint speed were mainly due to the improved neuro-muscular coordination and caused alterations in thetransfer of energy. Movements performed with maximal speed become more economical and so sprint speeds increased. Speed, treated as a motor ability, improves also due to proper strength training, and hence the observed improvement in the sprint test (Kotzamanidis et al. 2005). The general strength training during the preparation period, properly supported by core stability and functional exercises, is a solid foundation for increasing speed parameters.

The positive influence of the functional and core stability exercises on motor performance in this study may be due to a long-term, systematic training program. Our study's procedures when compared to the ones of Scibek et al. (2001),Stanton et al. (2004) and Tse et al. (2005) had different designs regarding the total duration of the intervention program (2 years vs. 6-8 weeks). Similarly, Barnes (2002) using various methods of strength training for runners, observed the importance of core strength development as the foundation for long-term dynamic muscular strength training and to maximize the propulsive forces developed by the power-producing legs.

In our opinion the functional and core stability exercises are necessary for optimal sport performance and should not be dismissed. Determination of the role of core strength/stability requires additional research and sportspecific means of determining its effectiveness.

\section{Conclusions}

The results of this study allow for the following conclusions:

1. Core stability and functional exercises implemented during the two-year program of football training are conducive to improvements in maximal strength in the analyzed muscle groups.

2. Core stability exercises and functional training has a positive effect on the sprint speed of female football players.

\section{References}

Barnes D. What type of strength training do distance runner do or need? Modern Athlete Coach. 2002; 40: 27-37.

Beam J.W. Rehabilitation including sport-specific functional progression for competitive athlete. Journal of Bodywork and Movement Therapies. 2002; 6 (4): 205-219.

Boyle M. Functional Training for Sports. Human Kinetics. 2004: 155-167.

Clark C.A. Integrated neuromuscular stabilization training. National Academy of Sports Medicine. 2001.

Duncan R.A., McNair P.J. Factors contribution to low back pain in rowers. Br J Sports Med. 2000: 34; 321-322.

Haynes W. Core stability and the unstable platform device. Journal of Bodywork and Movement Therapies. 2004: 88-103.

Kotzamanidis Ch., Chatzopoulos D., Michailidis C.H., Papaiakovou G., Patikas D. The Effect of a Combined High-Intensity Strength and Speed Training Program on the Running and Jumping Ability of Soccer Players. Journal of Strength and Conditioning Research. 2005; 19 (2), 369-375.

Nesser T.W., Huxel C.K., Tincher J.L., Okada T. The relationship between core stability and performance in division I football players. J Strength Cond Res. 2008; 22 (6): 1750-1754.

Paterno M.V., Myer G.D., Ford K.R., Hewett T.E. Neuromuscular training improves single-leg stability in young female athletes. Journal of Orthopedic and Sports Physical Therapy. 2004: 305-316.

Reed C.A., Ford K.R. The effects of isolated and integrated 'core stability' training on athletic performance measures: a systematic review. Sports Med. 2012: 697-706.

Sato K., Mokha M. Does Core Strength Training Influence Running Kinetics, Lower-Extremity Stability, and 5000-m Performance in Runners, J Strength Cond Res. 2009; 23 (1): 133-140. 
Ścibek J.S., Guskiewicz K.M., Prentice W.E., Mays S., Davis J.M. The effect of core stabilization training on functional performance in swimming. Master's thesis, University of North Carolina, Chapel Hill, 2001.

Sharmann S.A. Diagnosis and Treatment of Movement Impaired Syndromes. St. Louis, MO, Mosby. 2002: 121-129.

Sharrock C., Cropper J. A pilot study of core stability and athletic performance: is there a relationship. Int. J Sports Phys Ther. 2011; $6(2): 63-74$.

Stanton R., Reaburn P.R., Humphries B. The effect of short-term Swiss ball training on core stability and running economy. J Strength Cond Res. 18; 2004: 522-528.

Stein N. Stabilisierungsprogramme von den DFB-Juniorinnen bis zur Frauen-Nationalmanschaft. Fussballtrainning. 2008: 20-35.

Tse M.A., McManus A.M., Masters R.S.W. Development and validation of a core endurance intervention program: implications for performance in college-age rowers. J Strength Cond Res. 19; 2005: 547-552.

Wilson J.D., Dougherty C.P., Ireland M.L., Davis I.M. Corestability and its relationship to lower extremity function and injury. J Am Acad Orthop Surg. 13; 2005: 316-325.

Cite this article aS: Niewolna N., Zwierko T. The Effect of Core Stability and Functional Exercises on Selected Speed and Strength Parameters in Expert Female Footballers. Central European Journal of Sport Sciences and Medicine. 2015; 12 (4): $91-97$. 
